\title{
Factorial Composition of Counsellor Effectiveness Scale
}

\author{
Adeyemo Emily Oluseyi ${ }^{1, *} \&$ Shaba Veronica Oreoluwa ${ }^{1}$ \\ ${ }^{1}$ Dept of Educational Foundations and Counselling, Faculty of Education, Obafemi Awolowo University, Ile -Ife, \\ Nigeria \\ *Corresponding author: Dept of Educational Foundations and Counselling, Faculty of Education, Obafemi Awolowo \\ University, Ile -Ife, Nigeria. E-mail: seyiadeyemo2007@yahoo.com
}

Received: April 15, 2014

Accepted: April 23, $2014 \quad$ Online Published: July 31, 2014

doi:10.5430/wje.v4n4p61

URL: http://dx.doi.org/10.5430/wje.v4n4p61

\begin{abstract}
The study developed a set of items that could measure counsellor effectiveness. It reduced the initial set of variables related to counsellor effectiveness to such number of variables that are generally perceived as indicative of counsellor effectiveness and determined the factorial composition of the scale. in order to identify the major factors that underpin counsellor effectiveness with a view of developing an homogeneous items of counsellor effectiveness scale suitable for Nigeria Schools. The study design was exploratory using Principal Component Analysis (PCA) with interaction. The sample size consisted of 50 counsellors selected by convenience sampling from the population of counsellors in 148 schools in Ondo State as at the time of the study. Alongside, an initial 800 counsellee who were secondary school students were purposively selected from 12 secondary schools in six local government areas of the state. The instrument used for this study was Questionnaire that measured counsellor effectiveness. This consisted of an initial number of 51 items describing an effective counsellor in terms of personality characteristics, personal qualities, and performance indicators. These were derived from available description and characteristics of counsellor effectiveness in literatures. The responses were coded and analyzed using Principal Component Analysis. Items that failed to meet the baseline scores of eligibility into the final list were dropped. The final list consisted of 35 items were subjected to Principal Component Analysis which provided the initial factor. These were rotated using Orthogonal (Varimax) Method which yielded five underlying components of counsellor effectiveness. These were identified as expertness, sense of responsibility, pleasantness and integrity. The fifth factor could not be conceptualized from the regression weights and factor loadings of the items.
\end{abstract}

Keywords: factorial composition; counsellor; effectiveness; scale; factor loading

\section{Introduction}

Counselling connotes a relationship between a person who is trained, skilled, and composed called the counsellor and another person the client who is vulnerable and needs assistance. Generally, client are somehow reluctant to come to the counsellor for help. This may be due to the client personality, culture or even prejudice, being rather cynical about the process and outcome of the counselling relationship. In other words, the client may be concerned about whether or not the encountered with the counsellor will be effective.

Measurement of counseling effectiveness is a complex process intended to demonstrate the value, of counseling services. A number of criteria havebeen proposed to measure counselor effectiveness. Among these include the judgment by counselor trainees, global ratings by counselor supervisors, use of external criteria, workplace criteria and the judgment of clients. Counselling effectiveness relates not only to the personality of the counselor but also to the nature, mood, colour and direction of the counselilng interview. It also relates undoubtedly to the feelings, level, of satisfaction and happiness of the client at the end of the interview.

An early study(Stefflre, King and Leafgren, 1962) simply had the counsellor trainee nominated each other as effective counsellor and compared those most chosen with those least chosen. Later attention seemed to shift to the use of global ratings of effectiveness as the sole common measure. (these include studies by Kazienko and Neidt 1962, Wicas and Mahas 1966, Mc Daniel 1968, Mclain 1968 and Guberg, 1969). Their analysis generated a list of adjectives describing the good counsellor along the parameters of self-concept, motivation, value pattern and feelings 
about other people. From these they describe the composite personality of a good counsellor.

Jackson and Thompson (1971) compared counsellor effectiveness with measures of cognitive flexibility, tolerance of ambiguity, and attitudes towards self, people, and clients at counselling. The 73 school counsellor subjects were rated on effectiveness by evidence of client movement towards self-understanding, self acceptance, skills in satisfying needs, decision making skills, and specific goal attainment. The only significant finding was that effective counsellors were more positive in counselling rated attitudes than those who were least effective. However, it is possible that these attitudes are a consequence of, rather than the cause for being effective.

The effectiveness of counseling has been examined in several studies, Lambert, Cattni-Thompson (1996), Rowland, Godfrey, Bower, Clark, Heywood and Hardy( 2000) They discovered that generally counselling is effective while examining the process and outcome of clients undergoing therapy but it is apparent that while the majority of client improve, a minority remained unchanged and still others actually deteriorated. Effective counselling is a two way street. It takes a cooperative effort by both the person receiving counselling and the counsellor and it sometimes takes commitment to make difficult changes in behavior or thinking pattern. A capable counsellor must therefore possess a number of personal qualities and can be used to effectively support a client process. Ponto (2006) and Roy (2011) highlighted some personal qualities ofan effective counsellor. These are encouraging autistics, emotionally stable, empathetic caring, self awareness, self acceptance, positive self esteem, self realization, self disclosure, courageous, patient, non-judgmental, tolerance for ambiguity and spirituality. It is 'important that both the counsellor and the client must establish a good relationship that allows complete honesty about their thoughts and feelings.

In the school setting the work of the counselor includes helping students with subject selection, career choice study habit, selecting educational programmes and in dealing with personal and social concern. In all these the pertinent question is what makes a counsellor effective. There is therefore the need to develop a valid and usable scale to measure counsellor effectiveness in order to have a culturally relevant instrument that is designed for Nigerian schools. The Nigerian based scale will be able to address the fundamental variables that underlie counselling effectiveness in Nigeria. This will be done using factor analysis to determine the essential factor that predispose ecounsellor to being effective.

A factor analysis is a multivariable psychometric and statistical technique that has as its aim the explanation of the relationship among several correlated variables in terms of a few conceptually meaningful relatively independent factors. (Morrison, 1982)It is a method for determining the number and nature of the underlying variables in a set of measures. It extracts common factor variables from sets of measures. Factor analysis is a method of grouping together variables which have something in common. It is a process which enables the researcher to take a set of variables and reduce them to a smaller number of underlying factor which account for as many variables as possible. It detects structures and communalities in the relationship between variables. It enables researchers to identify where different variables are addressing the same underlying concept. For example, one variable could measure the price of a commodity in dollars and another could measure it in pound sterling, the underlying factor that unite both variables is price. It is a latent factor that is indicated by the two variables.

Factor analysis takes two main forms these are exploratory analysis and confirmatory factor analysis. The former refers to the use of factor analysis (Principal Component Analysis) to explore previously unknown grouping of variables to seek underlying patterns of groups or clustering i.e. the exploration and detection of pattern of variables with the view to the discovery of new concepts and a possible reduction of data. The confirmatory factor analysis is more stringent, testing a found set of factors against a hypothesized model of grouping and relationships i.e. the testing of hypotheses about the structuring of variables in terms of the expected number of significant factor loadings. Factor Analysis also take the form of a device used in the construction of indices to be used as a new variables in later analysis.

A test that measures one factor only is said to be factorial pure. A test that measure several factors is said to be saturated. One of the final outcome of a factor analysis is called a factor matrix which is a table of coefficient showing the relationship between the test and the underlying factors. The entries in the table are called factor loading. Communalities are entries that shows the sum of squares of the factor loading of a test or variable, it is an indication of its common factor variance. The single most distinctive characteristics of factor analysis is its data- reduction or data summarization capacity. Thus, given an array of correlation coefficient for a set of variables, factor -analysis technique shows whether some underlying pattern of relationships exists such that the data may be rearranged by components that may be taken as source variables accounting for the observed interrelations in the data.

Apart from the need to develop a valid and usable scale measuring counsellor effectiveness in Nigeria schools there is also the unsettled nature of counselor effectiveness i.e. the factor dimensions of the concept that form the 
underlying variables. There were expectations of the counsellors impact especially on educational matters affecting the students and if the fundamental variables that underlie counselling effectiveness in Nigeria are not inferred, there is the probability of placing inappropriate emphasis on some aspects of counsellor training or even minimizing or omitting important skills or activities that have high potentials for counsellor effectiveness. In addition, it is also possible that there are certain personality or environmental characteristics that can enhance counsellor effectiveness. The major purpose of this study therefore is to develop a counsellor effectiveness scale suitable for Nigerian schools and validate the scale using factor analytic technique. Specifically, the objectives of the study are to:

(i) develop an homogeneous items of counsellor effectiveness scale suitable for Nigeria schools

(ii) reduce an initial set of variables related to counsellor effectiveness to such number of variables that are generally perceived as indicative of counsellor effectiveness and

(iii) find out the factorial composition of the counsellor effectiveness scale.

This will provide a veritable scale for evaluators and counsellor trainers to measure counsellor effectiveness in Nigeria schools.

\section{Methodology}

The study design was exploratory using Principal Component Analysis (PCA) with interaction. The communalities were estimated from the multiple correlation coefficients. Items with high percentages frequencies were used to report the PCA with final selection according to valid percentage scores. The population consisted of secondary school students and counsellors. The sample size consisted of 50 counsellors selected by convenience sampling from the population of counsellors in 148 schools in Ondo state as at the time of the study. Of these, 38 eventually participated in the study. Alongside, an initial 800 clients who were secondary school students were purposively selected from 12 secondary schools in six local government areas of Ondo state. The students had patronized their own school counsellor at least twice in the session the research was carried out. The final students sample size who took part in the study was 575. The instrument used for this study was Questionnaire that measure counseling effectiveness. This consisted of an initial number of 51 items describing an effective counsellor in terms of personality characteristics, personal qualities, and performance indicators. These were derived from available description and characteristics of counsellor effectiveness in literatures (Marin Roy 2011, Ponto, 2006, and Thomson, 1996). 720 students returned the completed questionnaire while 575 were completed appropriately. The responses were coded and analyzed using Principal Component Analysis.

\section{Results}

\subsection{Objective I}

To develop an homogeneous items of counsellor effectiveness scale suitable for Nigeria Schools.

Table 1. Frequencies of Homogeneous Items of the Counsellor Effectiveness Scale

\begin{tabular}{|c|c|c|c|c|c|c|c|}
\hline \multirow[t]{2}{*}{$\mathbf{S} / \mathbf{N}$} & \multirow{2}{*}{$\begin{array}{l}\text { ITEMS } \\
\text { An effective counsellor:- }\end{array}$} & \multicolumn{2}{|c|}{ Agree } & \multicolumn{2}{|c|}{ Disagree } & \multicolumn{2}{|c|}{ Can't say } \\
\hline & & $\mathbf{N}$ & $\%$ & $\mathbf{N}$ & $\%$ & $\mathbf{N}$ & $\%$ \\
\hline 1 & is impatient towards sluggish client & 76 & 13.2 & 204 & 35.5 & 275 & 47.8 \\
\hline 2 & shows adequate concern about client problems & 413 & 71.8 & 83 & 14.4 & 66 & 11.5 \\
\hline 3 & shows alertness of mind & 389 & 67.7 & 90 & 15.7 & 81 & 14.1 \\
\hline 4 & is tolerant of irrational behavior of clients & 284 & 49.4 & 168 & 29.2 & 101 & 17.6 \\
\hline 5 & usually hastens to conclude an interview & 82 & 14.3 & 178 & 31 & 293 & 51 \\
\hline 6 & is not flexible & 118 & 20.5 & 146 & 25.4 & 284 & 49 \\
\hline 7 & keep his records adequately & 425 & 74 & 63 & 11 & 68 & 11 \\
\hline 8 & has integrity & 377 & 66 & 89 & 16 & 88 & 15 \\
\hline 9 & protects the privacy of clients & 376 & 65 & 104 & 18 & 78 & 14 \\
\hline 10 & is not erratic & 262 & 46 & 186 & 32 & 107 & 19 \\
\hline 11 & is easily bored & 86 & 15 & 164 & 29 & 302 & 53 \\
\hline 12 & is pleasant & 387 & 67 & 100 & 17 & 69 & 12 \\
\hline 13 & exhibit warmth towards client & 352 & 61 & 128 & 22 & 76 & 13 \\
\hline 14 & sometimes look down on clients & 90 & 16 & 173 & 30 & 292 & 51 \\
\hline
\end{tabular}




\begin{tabular}{|c|c|c|c|c|c|c|c|}
\hline 15 & appears patronizing & 365 & 64 & 110 & 19 & 77 & 13 \\
\hline 16 & has self control & 403 & 70 & 78 & 14 & 77 & 13 \\
\hline 17 & is trustworthy & 405 & 70 & 75 & 13 & 79 & 14 \\
\hline 18 & keeps appointments & 409 & 71 & 85 & 15 & 64 & 11 \\
\hline 19 & shows empathy towards clients & 354 & 62 & 99 & 17 & 102 & 18 \\
\hline 20 & appears versatile in professional matters & 316 & 55 & 128 & 22 & 108 & 19 \\
\hline 21 & presents himself as if he has all the answers & 281 & 49 & 158 & 28 & 113 & 20 \\
\hline 22 & is impulsive & 300 & 52 & 125 & 22 & 122 & 21 \\
\hline 23 & $\begin{array}{l}\text { is reluctant to confront a client with the hisof reality of his } \\
\text { problem if this will make the client client uncomfortable }\end{array}$ & 314 & 55 & 127 & 22 & 103 & 18 \\
\hline 24 & $\begin{array}{l}\text { readily offers practical and concrete hints } \\
\text { that are helpful in decision making to client }\end{array}$ & 369 & 64 & 96 & 17 & 83 & 14 \\
\hline 25 & create a conducive atmosphere for clients & 362 & 63 & 81 & 14 & 108 & 19 \\
\hline 26 & shows remarkable resourcefulness & 362 & 63 & 112 & 20 & 75 & 13 \\
\hline 27 & attends to clients promptly & 374 & 65 & 104 & 18 & 76 & 13 \\
\hline 28 & has a stable temperament & 318 & 55 & 131 & 23 & 104 & 18 \\
\hline 29 & show a great level of self-understanding & 350 & 61 & 127 & 22 & 70 & 12 \\
\hline 30 & appears disturbed by clients presence & 241 & 42 & 224 & 39 & 83 & 14 \\
\hline 31 & is unstable to go the extra mile to help & 275 & 48 & 168 & 29 & 106 & 18 \\
\hline 32 & always demonstrate a cheerful countenance & 352 & 61 & 113 & 20 & 79 & 14 \\
\hline 33 & does not lack necessary tools to assist clients & 379 & 66 & 95 & 17 & 74 & 13 \\
\hline 34 & makes accurate judgment & 382 & 66 & 93 & 16 & 73 & 13 \\
\hline 35 & easily gets things done & 381 & 66 & 86 & 15 & 81 & 14 \\
\hline 36 & is very courteous & 372 & 65 & 97 & 17 & 80 & 14 \\
\hline 37 & is a good listener & 356 & 62 & 117 & 20 & 75 & 13 \\
\hline 38 & is likeable & 357 & 62 & 106 & 18 & 85 & 15 \\
\hline 39 & is full of himself & 292 & 51 & 157 & 27 & 96 & 17 \\
\hline 40 & uses appropriate questioning techniques & 359 & 62 & 102 & 18 & 85 & 15 \\
\hline 41 & appreciate clients' feeling & 368 & 64 & 88 & 15 & 90 & 16 \\
\hline 42 & is sympathetic & 377 & 66 & 88 & 15 & 78 & 14 \\
\hline 43 & helps clients to discover themselves & 376 & 65 & 81 & 14 & 84 & 15 \\
\hline 44 & makes interview stimulating & 327 & 57 & 113 & 20 & 101 & 18 \\
\hline 45 & accept a client as he is & 324 & 56 & 134 & 23 & 80 & 14 \\
\hline 46 & is not well organized & 239 & 42 & 226 & 39 & 82 & 14 \\
\hline 47 & has a friendly disposition & 315 & 55 & 131 & 23 & 94 & 16 \\
\hline 48 & respect clients' feelings & 341 & 59 & 108 & 19 & 88 & 15 \\
\hline 49 & is genuine in his propositions to clients & 314 & 55 & 101 & 18 & 111 & 19 \\
\hline 50 & works towards clients 'self- fulfillment & 348 & 61 & 91 & 16 & 85 & 15 \\
\hline 51 & terminates interviews abruptly & 227 & 40 & 125 & 22 & 149 & 26 \\
\hline
\end{tabular}

Table I presents all the initial items in the Counsellor Effectiveness Scale that was administered to the subjects. The responses were analyzed using percentages. The benchmark percentage was 56.All positive items with percentage agreement of 55 or less were dropped while those with higher scores were retained. The scoring for negative items were reversed.

\subsection{Objective Two}

To reduce an initial set of variables related to counselor effectiveness to such number of variables that are generally perceived as indicative of counsellor effectiveness. 
Presented below is a the final list of the selected items

\begin{tabular}{|c|c|c|c|c|c|c|c|}
\hline \multirow[t]{2}{*}{$\mathbf{S} / \mathbf{N}$} & \multirow{2}{*}{$\begin{array}{l}\text { ITEMS } \\
\text { An effective counsellor:- }\end{array}$} & \multicolumn{2}{|c|}{ Agree } & \multicolumn{2}{|c|}{ Disagree } & \multicolumn{2}{|c|}{ Can't say } \\
\hline & & $\mathbf{N}$ & $\%$ & $\mathbf{N}$ & $\%$ & $\mathbf{N}$ & $\%$ \\
\hline 2 & shows adequate concern about client problems & 413 & 71.8 & 83 & 14.4 & 66 & 11.5 \\
\hline 3 & shows alertness of mind & 389 & 67.7 & 90 & 15.7 & 81 & 14.1 \\
\hline 7 & keep his records adequately & 425 & 74 & 63 & 11 & 68 & 11 \\
\hline 8 & has integrity & 377 & 66 & 89 & 16 & 88 & 15 \\
\hline 9 & protects the privacy of clients & 376 & 65 & 104 & 18 & 78 & 14 \\
\hline 12 & is pleasant & 387 & 67 & 100 & 17 & 69 & 12 \\
\hline 13 & exhibit warmth towards client & 352 & 61 & 128 & 22 & 76 & 13 \\
\hline 15 & appears patronizing & 365 & 64 & 110 & 19 & 77 & 13 \\
\hline 16 & has self control & 403 & 70 & 78 & 14 & 77 & 13 \\
\hline 17 & is trustworthy & 405 & 70 & 75 & 13 & 79 & 14 \\
\hline 18 & keeps appointments & 409 & 71 & 85 & 15 & 64 & 11 \\
\hline 19 & shows empathy towards clients & 354 & 62 & 99 & 17 & 102 & 18 \\
\hline 20 & appears versatile in professional matters & 316 & 55 & 128 & 22 & 108 & 19 \\
\hline 24 & $\begin{array}{l}\text { readily offers practical and concrete hints } \\
\text { that are helpful in decision making to client }\end{array}$ & 369 & 64 & 96 & 17 & 83 & 14 \\
\hline 25 & create a conducive atmosphere for clients & 362 & 63 & 81 & 14 & 108 & 19 \\
\hline 26 & shows remarkable resourcefulness & 362 & 63 & 112 & 20 & 75 & 13 \\
\hline 27 & attends to clients promptly & 374 & 65 & 104 & 18 & 76 & 13 \\
\hline 28 & has a stable temperament & 318 & 55 & 131 & 23 & 104 & 18 \\
\hline 29 & show a great level of self-understanding & 350 & 61 & 127 & 22 & 70 & 12 \\
\hline 33 & does not lack necessary tools to assist clients & 379 & 66 & 95 & 17 & 74 & 13 \\
\hline 34 & makes accurate judgment & 382 & 66 & 93 & 16 & 73 & 13 \\
\hline 35 & easily gets things done & 381 & 66 & 86 & 15 & 81 & 14 \\
\hline 36 & is very courteous & 372 & 65 & 97 & 17 & 80 & 14 \\
\hline 37 & is a good listener & 356 & 62 & 117 & 20 & 75 & 13 \\
\hline 38 & is likeable & 357 & 62 & 106 & 18 & 85 & 15 \\
\hline 40 & uses appropriate questioning techniques & 359 & 62 & 102 & 18 & 85 & 15 \\
\hline 41 & appreciate clients' feeling & 368 & 64 & 88 & 15 & 90 & 16 \\
\hline 42 & is sympathetic & 377 & 66 & 88 & 15 & 78 & 14 \\
\hline 43 & helps clients to discover themselves & 376 & 65 & 81 & 14 & 84 & 15 \\
\hline 44 & makes interview stimulating & 327 & 57 & 113 & 20 & 101 & 18 \\
\hline 45 & accept a client as he is & 324 & 56 & 134 & 23 & 80 & 14 \\
\hline 47 & has a friendly disposition & 315 & 55 & 131 & 23 & 94 & 16 \\
\hline 49 & is genuine in his propositions to clients & 314 & 55 & 101 & 18 & 111 & 19 \\
\hline 50 & works towards clients 'self- fulfillment & 348 & 61 & 91 & 16 & 85 & 15 \\
\hline
\end{tabular}

Thus item 1:-'is impatient towards a sluggish client' was dropped as bad item with 13\% of the client agreed that the item was acceptable. About half the client $48 \%$ opted for 'can't say' which suggested the item was ambiguous. Item 4 which read 'is tolerant of irrational behavior of client' was dropped having 49\%, Agree 29\%, Disagree and 18 can't say. Another item that was dropped was item 5 'usually hasten to conclude an interview' which had Agree, 31\%, Disagree and 51\% Can't say. Other items that failed to meet up were items 6, 19, 11, 14, 21, 22, 23, 30, 31, 39, 46, and 51 making 14 items altogether. Items 41 and 48 were similar. Hence 35 items which was $68.6 \%$ of the initial items seemed acceptable to the clients as describing an effective counsellor.

\subsection{Objective Three}

\section{To find out the factorial composition of the Counsellor Effectiveness Scale.}

This section highlighted the new factors that can be inferred from the factor loadings of each variable(item) of the Counsellor Effectiveness Scale. The ultimate desire was to find out the factors that were measured by the new scale and the variables which belong to each factor. Table 2 presented the principal factor matrix which gave the correlation coefficient between each variable and each factor. 
Table 2. Initial Factor Matrix of Inferred Factor and Item Variable

\begin{tabular}{|c|c|c|c|c|c|c|}
\hline \multirow{2}{*}{$\begin{array}{l}\text { Original } \\
\text { Items }\end{array}$} & \multicolumn{6}{|c|}{ Factors } \\
\hline & F1 & $\mathrm{F} 2$ & F3 & $\mathrm{F} 4$ & F5 & $\begin{array}{c}\text { Communialities } \\
(\mathrm{h}\end{array}$ \\
\hline 2 & 0.561 & 0.339 & 0.026 & 0.318 & 0.101 & 0.542 \\
\hline 3 & 0.497 & 0.356 & 0.195 & 0.051 & 0.126 & 0.430 \\
\hline 7 & 0.606 & 0.231 & 0.083 & 0.344 & 0.061 & 0.549 \\
\hline 8 & 0.479 & 0.321 & 0.092 & 0.125 & 0.043 & 0.359 \\
\hline 9 & 0.528 & 0.239 & 0.167 & 0.179 & 0.069 & 0.401 \\
\hline 12 & 0.562 & 0.283 & 0.034 & 0.159 & 0.127 & 0.439 \\
\hline 13 & 0.523 & 0.347 & 0.055 & 0.083 & 0.107 & 0.414 \\
\hline 15 & 0.489 & 0.350 & 0.136 & 0.038 & 0.245 & 0.442 \\
\hline 16 & 0.639 & 0.371 & 0.117 & 0.115 & 0.178 & 0.539 \\
\hline 17 & 0.575 & 0.288 & 0.056 & 0.147 & 0.101 & 0.448 \\
\hline 18 & 0.602 & 0.277 & 0.040 & 0.157 & 0.001 & 0.465 \\
\hline 19 & 0.486 & 0.396 & 0.011 & 0.092 & 0.166 & 0.429 \\
\hline 20 & 0.439 & 0.353 & 0.014 & 0.522 & 0.007 & 0.604 \\
\hline 24 & 0.529 & 0.048 & 0.013 & 0.048 & 0.063 & 0.288 \\
\hline 25 & 0.563 & 0.183 & 0.100 & 0.154 & 0.018 & 0.384 \\
\hline 26 & 0.588 & 0.179 & 0.261 & 0.229 & 0.067 & 0.502 \\
\hline 27 & 0.570 & 0.098 & 0.295 & 0.072 & 0.036 & 0.429 \\
\hline 28 & 0.491 & 0.193 & 0.075 & 0.288 & 0.180 & 0.399 \\
\hline 29 & 0.553 & 0.115 & 0.158 & 0.199 & 0.041 & 0.386 \\
\hline 32 & 0.604 & 0.187 & 0.290 & 0.055 & 0.200 & 0.528 \\
\hline 33 & 0.578 & 0.226 & 0.303 & 0.107 & 0.236 & 0.544 \\
\hline 34 & 0.636 & 0.205 & 0.305 & 0.046 & 0.130 & 0.558 \\
\hline 35 & 0.664 & 0.189 & 0.167 & 0.208 & 0.053 & 0.551 \\
\hline 36 & 0.607 & 0.209 & 0.225 & 0.028 & 0.085 & 0.471 \\
\hline 37 & 0.645 & 0.253 & 0.061 & 0.109 & 0.063 & 0.500 \\
\hline 38 & 0.643 & 0.256 & 0.079 & 0.179 & 0.062 & 0.522 \\
\hline 40 & 0.052 & 0.211 & 0.171 & 0.166 & 0.013 & 0.526 \\
\hline 41 & 0.643 & 0.262 & 0.006 & 0.104 & 0.059 & 0.497 \\
\hline 42 & 0.679 & 0.283 & 0.013 & 0.045 & 0.029 & 0.544 \\
\hline 43 & 0.674 & 0.297 & 0.096 & 0.050 & 0.026 & 0.555 \\
\hline 44 & 0.669 & 0.262 & 0.169 & 0.094 & 0.089 & 0.561 \\
\hline 45 & 0.633 & 0.301 & 0.089 & 0.068 & 0.134 & 0.522 \\
\hline 47 & 0.603 & 0.226 & 0.245 & 0.000 & 0.008 & 0.475 \\
\hline 49 & 0.562 & 0.222 & 0.321 & 0.208 & 0.085 & 0.518 \\
\hline 50 & 0.583 & 0.237 & 0.186 & 0.024 & 0.120 & 0.445 \\
\hline
\end{tabular}

From the table, the correlations ranged between 0 (for variable 47, factor 4 ) and 0.679 (for variable 42 , factor 1 ) Factor 1 seemed to have the highest correlations for all the variables (between 0.439 and 0.679), while the highestloading for the other factor was 0.396 (factor 2, variable 19). Altogether, fivefactors were identified from all the variables. The communalities $\mathrm{h}^{2}$, that were associated with each variable were also presented These indicate the total variance of the variable accounted for by the combination of all the factors. In table twoh ${ }^{2}$ ranged from 0.288 to 0.604 , this suggested that many variables in the set shared the variance of a particular variable. Essentially, these pointed to the homogeneity of the variables. To make a more accurate deduction of the factors therefore, a varimax rotation of the factor matrix was performed with iteration. The result is as presented below in Table 3 . 
Table 3. Varimax Rotated Factor Matrix

\begin{tabular}{|c|c|c|c|c|c|}
\hline \multirow[b]{2}{*}{ Items } & \multicolumn{5}{|c|}{ Factors } \\
\hline & F1 & F2 & F3 & F4 & F5 \\
\hline 2 show adequate concern & & 0.660 & & & \\
\hline 3 show alertness of mind & & 0.565 & & & \\
\hline 7 keeps record adequately & & 0.668 & & & \\
\hline 8has integrity & & 0.376 & & 0.413 & \\
\hline 9protects privacy of clients & & 0.559 & & & \\
\hline 12 is pleasant & & 0.591 & & & \\
\hline 13exhibits warmth towards people & & 0.442 & & 0.411 & \\
\hline 15appears patronizing & & 0.529 & & 0.309 & \\
\hline 16has self control & & 0.594 & & & \\
\hline 17 is trust worthy & & 0.579 & & & \\
\hline 18keeps appointments & & 0.574 & & & \\
\hline 19shows empathy towards clients & & 0.429 & & 0.427 & \\
\hline 20 is versatile in professional matters & & & & 0.729 & \\
\hline 24readily offers helpful hints to clients & & 0.538 & & & \\
\hline 25 create a conducive atmosphere & & 0.354 & & 0.394 & \\
\hline 26shows remarkable resourcefulness & & & 0.406 & 0.481 & \\
\hline 27attends to clients promptly & & 0.363 & 0.476 & & \\
\hline 28has a stable temperament & & & & 0.516 & \\
\hline 29shows a great level of self understanding & & & 0.322 & 0.412 & \\
\hline 32 always demonstrate a cheerful countenance & 0.336 & & 0.601 & & \\
\hline 33 does not lack necessary tools to assist clients & 0.367 & & 0.647 & & \\
\hline 34 makes accurate judgment & 0.370 & & 0.603 & & \\
\hline 35 easily gets things done & 0.430 & & 0.517 & & \\
\hline 36 is very courteous & 0.397 & & 0.515 & & \\
\hline 37 is a good listener & 0.608 & & & & \\
\hline 38 is likeable & 0.570 & & 0.336 & & \\
\hline 40 uses appropriate questioning techniques & 0.632 & & & & \\
\hline 41 appreciate clients' feeling & 0.562 & & 0.341 & & \\
\hline 42 is sympathetic & 0.585 & & 0.393 & & \\
\hline 43helps clients to discover themselves & 0.657 & & & & \\
\hline 44 makes interview stimulating & 0.649 & & & & \\
\hline 45 accept a client as he is & 0.637 & & & & \\
\hline 47 has a friendly disposition & 0.626 & & & & \\
\hline 49 is genuine in his propositions to clients & 0.665 & & & & \\
\hline 50 works towards clients 'self- fulfillment & 0.612 & & & & \\
\hline
\end{tabular}

The table contains the terminal solution of the orthogonally rotated factor. Since it is an orthogonal factor matrix, the coefficient in the table present both regression weights and correlation coefficient of factors which describe a given variable. The five columns in table 4 therefore stand for the factors or hypothetical constructs yet to be named. All variables are normalized. Thus for variable 1 , one can have:-var. $2=0.116 \mathrm{~F} 1 \mathrm{X} 0.660 \mathrm{~F} 2 \times 0.239 \mathrm{~F} 3 \mathrm{X} 0.090 \mathrm{~F} 4 \mathrm{X}$ $0.163 \mathrm{~F} 5$.

From the equation above, it was obvious that the most important determinant of var. 1 is factor 2 . and the influence of each of the other common factor was negligible. Likewise, the only significant common factor for var.3 was factor 2.By reading every row in the same manner, we could describe the linear composition of each variable in terms of five hypothetical factors.

Except for var.15,19,25,26,27,2932,33,34,35,36,38,41 and 42, all the other variables load significantly only on one factor. Cases of moderate double loadings such as Vars.1,19,25,26,27,29, suggested factorial complexity; that is the variables measure more than one theoretical dimension. The important of a given factor for a particular variable couldbe expressed interms of the variance in the variable that couldbe accounted for by the factor. Thus the variance of Var. 2 accounted by factor 2 is $0.660^{2}=0.4356 \mathrm{i}$ e $43.6 \%$ of the total variance is accounted for by Factor 2 . Likewise, 
the variance of a variable accounted for by all the factors was given by the sun of squares of the respective factor loadings.

From the regression weights in table 3 , the following factors can be generated together with the associated variables as presented in Table 4.

Table 4. Factor Dimension of the Counsellor Effectiveness Scale

\begin{tabular}{ll}
\hline Factor 1 & Expertness \\
& Vars. 3,19,20,24,26,34,35,37,40,43,44,45,50. \\
Factor 2 & Sense of Responsibility \\
& Vars. 7,9,18,27,33. \\
Factor 3 & Pleasantness \\
& Vars. 12,13,15,16,25,28,32,36,38,41,42,47 \\
Factor 4 & Integrity \\
& Vars. 2,8,17,29,49. \\
Factor 5 & Undefined \\
\hline
\end{tabular}

On the $5^{\text {th }}$ factor, an examination of the regression weights under column F5 of Table 4 clearly suggested that no item of the counselor effectiveness scale covered the unnamed factor.

\section{Discussion}

The result of client rating of the initial 51 items of the Counselor Effectiveness scale led to the rejection of 16 of the items, reducing the final list to 35 . Items that were rejected included those that appear to have double negatives (e.g. item 1), those portray negativity (e.g. items $6,10,31,46$.) or those whose meanings were not precise (e.g. item 4.) Yet others seemed to the client as typical of an effective counselor e.g. items 9,11,14,21,22.) The number of items that were retained appear to be large enough in size in terms of enhancing the reliability of the scale and not as large as to be boring to complete by future respondents. Furthermore, the factorial composition indicated that the items relating to a particular underlying factor in counsellor effectiveness were not in serial order on the scale.

A further examination of the items indicated that the items that were of greater concern and importance to the client who responded to the item touched not only on the personality of the ideal effective counselor (e,g. Items $12,28,47$,) but also on his/her character ( e.g. Items 8,17,48) and his/her performance (e.g. items 7,19,24,25,and 34.) All of these were consistent with the previous characterization of effective Counsellor as cited by Ponto (2006) and Roy (2011).

On the factorial composition of the scale, five factors were identified by the factor weightsof each variable or items of the scale. Four of these factors have been named as expertness, sense of responsibility, pleasantness, and integrity. Expertness had 13 variables. These variables were:-Var.3,19,20,24,26,34,35,37,40,43,44, 45 and 50. Normally, the composition of each factor was conceptualized by considering the construct that had a high capacity to draw attention to the fifth factor yet to be named. This was because the variable did not converge on this factor. The implication was that the envisaged counsellor effectiveness scale had a few other variables that were not tapped by the present instrument and which when collapsed into a factor would be similar to but distinct from the named four factors.

\section{References}

Jachson, M., \& Thompson, 1. (1971). Effective Counsellor; Characteristics and Attitudes. Journal of Counselling Psychology, 18, 249-254. http://dx.doi.org/10.1037/h0030862

Kazienko, L, W., \& Nedit, C. O. (1962). Self -descriptions of Good and Poor Counsellor Trainees. Counsellor Education and Supervision, 1, 106-123. http://dx.doi.org/10.1002/j.1556-6978.1962.tb00337.x

Lambert, M. J., \& CATTANI-Thompson, K. (1996). Current Fingings Regarding the Effectiveness of Counselling: Implication for Practice. Journal of Counsellingand Development, 74(6), 601-609. http://dx.doi.org/10.1002/j.1556-6676.1996.tb02299.x

Lindern, J.,D., Stone, S., C., \& Shertzer, B. (1965). Development and Evaluation of Inventory for Rating Counselling. 
Personnel and Guidance Journal, 44, 267-276. http://dx.doi.org/10.1002/j.2164-4918.1965.tb03516.x

McDaniel, S., W. (1967). Counsellor Selection: An Evaluation of Instruments Counsellor. Education and Supervision, 12, 123-129.

Morrison, D., F. (1982). Multivariate Statistical Methods. Tokyo: McGraw-Hill International Book Company.

Nelson, M., Herlihy, B., \& Oescher, J. (2002). A survey of counselor attitudes towardssex offender. Journal of Mental Health Counseling, 24(1), 51-58.

Ponto.L. (2006). Characteristics of Effective Counselling, Psch.Central. Retrieved on March 5, 2014 from http;//psyhcentral./com lib/characteristics-of-effective counseling/00093

Rowland, N., Godfrey C., Bowe, P., Mellon-Clark, J., Heywood, P., \& Hardy, P. (2000). Counselling in Primary Care: A Systematic Review of the Research Evidence. British Journal of Guidance and Counselling, 28(2), 216-233. http://dx.doi.org/10.1080/03069880050013511

Roy, M. (2011). Qualities of a good Counsellor. Psychological base of Education.

Stefflre, B., King. P., \& Leafgreen, F. (1962). Characteristics of Counsellor Judged Effective by their Peer. Journal of Counselling Psychology, 9, 335-340. http://dx.doi.org/10.1037/h0041695 